\title{
Occupational Therapy in Primary Care - Barriers, Pivots, and Outcomes: A pilot study
}

Sue Dahl-Popolizio

Arizona State University, sue.dahlpopolizio@asu.edu

Gretchen Anne Roman

Arizona State University, garoman@asu.edu

Felicia Trembath

Arizona State University, ftrembat@asu.edu

Bradley Doebbeling

Arizona State University, Doebbeling@asu.edu

Alyssa Concha-Chavez

Northern Arizona University, alyssa.concha-chavez@nau.edu

Follow this and additional works at: https://nsuworks.nova.edu/ijahsp

Part of the Other Medicine and Health Sciences Commons

\section{Recommended Citation}

Dahl-Popolizio S, Roman G, Trembath F, Doebbeling B, Concha-Chavez A. Occupational Therapy in Primary Care -- Barriers, Pivots, and Outcomes: A pilot study. The Internet Journal of Allied Health Sciences and Practice. 2021 Jan 01;19(1), Article 16.

This Manuscript is brought to you for free and open access by the College of Health Care Sciences at NSUWorks. It has been accepted for inclusion in Internet Journal of Allied Health Sciences and Practice by an authorized editor of NSUWorks. For more information, please contact nsuworks@nova.edu. 


\section{Occupational Therapy in Primary Care - Barriers, Pivots, and Outcomes: A pilot study}

\section{Abstract ABSTRACT}

Purpose: Habits, roles, and routines are important behaviors that affect lifestyle and can lead to the development of chronic disease such as diabetes mellitus. Primary care physicians (PCPs) have limited time, suggesting an interprofessional team approach would be beneficial in helping patients modify behaviors for the prevention and treatment of chronic disease. Occupational therapists (OTs) specialize in addressing health behaviors, and literature supports including OTs on the primary care team to improve the self-management techniques of patients with chronic disease. This study was guided by Lifestyle Redesign ${ }^{\circledR}$, an evidence-based program that addresses the health behaviors of patients with diabetes in primary care. We aimed to improve health outcomes by combining an OT-led lifestyle modification program with patient-centered treatment recommendations from an external interprofessional team. We hypothesized that the health outcomes of patients with diabetes in primary care would improve after participating in an OT-led interprofessional lifestyle modification program, and that reimbursement for services would be obtainable. Method: Two PCPs in community practice initially agreed to involve an OT on their primary care team. Due to reimbursement concerns, the PCPs later preferred to refer patients to receive the OT-led intervention at an offsite clinic, rather than onsite at the primary care practice. Health outcomes were measured pre- and post-intervention using industry standard assessments and biometrics. Descriptive and non-parametric statistics were used to evaluate change. Results: Thirty-one patients with diabetes were referred, and three $(9.7 \%)$ participated in the offsite lifestyle modification program. While statistical significance was not achieved $(p \geq 0.10)$, trends toward individual improvement were noted for occupational performance and satisfaction and empowerment, and reimbursement was received from the third-party payers. Conclusions: Patient participation in this study was consistent with participation rates for offsite behavioral health referrals. An offsite OT-led interprofessional lifestyle modification program demonstrated potential for meaningful change and services were reimbursed. These findings support practice redesign efforts to include OTs as part of an integrated primary care model. Offering onsite services will increase patient accessibility to care and improve referral completion rates, thus providing OTs the opportunity to further demonstrate the efficacy of delivering chronic disease management in primary care.

\section{Author Bio(s)}

Sue Dahl-Popolizio, DBH, OTR/L is a Clinical Associate Professor at Arizona State University (ASU), and a Program Coordinator of the Doctor of Behavioral Health Program in the College of Health Solutions at ASU. She is also a licensed occupational therapist.

Gretchen Roman, PT, DPT, PhD is an academic researcher affiliated with Arizona State University and a licensed physical therapist.

Felicia Trembath, PhD, MPH is an epidemiologist and Clinical Assistant Professor in the Public Health Department at Midwestern University.

Bradley Doebberling, MD, MSc. is professor of Science of Health Care Delivery and Biomedical Informatics in the College of Health Solutions at Arizona State University.

Alyssa Concha-Chavez, OTD is a Program Coordinator at Northern Arizona University and a licensed occupational therapist. 


\section{Acknowledgements}

We would like to recognize the following collaborators who served as part of this study's interprofessional team: Matthew Buman, PhD, Caitlin Cameron, PharmD, Melissa Coronado, OTS, Andrea Durand, DBH, LCSW, Jessica Lehmann, MS, RDN, Lesley Manson, PsyD, Miranda Materi, OTR/L, CHT, and Connor Swanson, OTS. Thank you for your time and consultation. Your contributions toward improving the health outcomes of patients with diabetes in primary care were greatly appreciated. 


\title{
IIIAHSP \\ The Internet Journal of Allied Health Sciences and Practice \\ Dedicated to allied health professional practice and education
}

Vol. 19 No. 1 ISSN 1540-580X

\section{Occupational Therapy in Primary Care -- Barriers, Pivots, and Outcomes: A pilot study}

\author{
Sue Dahl-Popolizio ${ }^{1}$ \\ Gretcvhen Anne Roman ${ }^{1}$ \\ Felicia Trembath ${ }^{1}$ \\ Braqdley Doebbeling ${ }^{1}$ \\ Alyssa Concha-Chavez² \\ 1. Arizona State University \\ 2. Northern Arizona University \\ United States
}

\begin{abstract}
Purpose: Habits, roles, and routines are important behaviors that affect lifestyle and can lead to the development of chronic disease such as diabetes mellitus. Primary care physicians (PCPs) have limited time, suggesting an interprofessional team approach would be beneficial in helping patients modify behaviors for the prevention and treatment of chronic disease. Occupational therapists (OTs) specialize in addressing health behaviors, and literature supports including OTs on the primary care team to improve the self-management techniques of patients with chronic disease. This study was guided by Lifestyle Redesign®, an evidence-based program that addresses the health behaviors of patients with diabetes in primary care. We aimed to improve health outcomes by combining an OT-led lifestyle modification program with patient-centered treatment recommendations from an external interprofessional team. We hypothesized that the health outcomes of patients with diabetes in primary care would improve after participating in an OT-led interprofessional lifestyle modification program, and that reimbursement for services would be obtainable. Method: Two PCPs in community practice initially agreed to involve an OT on their primary care team. Due to reimbursement concerns, the PCPs later preferred to refer patients to receive the OT-led intervention at an offsite clinic, rather than onsite at the primary care practice. Health outcomes were measured pre- and post-intervention using industry standard assessments and biometrics. Descriptive and non-parametric statistics were used to evaluate change. Results: Thirty-one patients with diabetes were referred, and three (9.7\%) participated in the offsite lifestyle modification program. While statistical significance was not achieved $(p \geq 0.10)$, trends toward individual improvement were noted for occupational performance and satisfaction and empowerment, and reimbursement was received from the third-party payers. Conclusions: Patient participation in this study was consistent with participation rates for offsite behavioral health referrals. An offsite OT-led interprofessional lifestyle modification program demonstrated potential for meaningful change and services were reimbursed. These findings support practice redesign efforts to include OTs as part of an integrated primary care model. Offering onsite services will increase patient accessibility to care and improve referral completion rates, thus providing OTs the opportunity to further demonstrate the efficacy of delivering chronic disease management in primary care.
\end{abstract}

Keywords: behavioral health; chronic disease; diabetes; interprofessional; lifestyle modification; occupational therapy; primary care; reimbursement 


\section{INTRODUCTION}

Chronic conditions account for more than $75 \%$ of healthcare costs in the United States.1,2 Habits, roles, routines, culture, family, and value systems can affect lifestyle behaviors and lead to the development of chronic disease. ${ }^{3}$ Modification of such behaviors has been shown to prevent and manage chronic disease. ${ }^{2,3}$ As primary care is the preferred setting for chronic disease management, and lifestyle behavior change does not require the skill set of a physician, primary care practices should consider an interprofessional team approach to better address the patient behaviors that interfere with adherence to medical treatment recommendations. ${ }^{3,4}$ Occupational therapists (OTs) specialize in addressing the lifestyle behaviors associated with chronic conditions, such as diabetes mellitus or cardiac disease. ${ }^{3-7}$ Additionally, OTs are well poised to address behavioral health issues, like anxiety, depression, and other mental health concerns that occur in the day-to-day lives of patients, and thus, are common presenting concerns in primary care. ${ }^{2,3}$ Addressing lifestyle behaviors and behavioral health issues, as well as identifying barriers to behavior modification and providing strategies to overcome these barriers, are the skilled-services that OTs can contribute to interprofessional primary care teams.

Occupational therapy has demonstrated effectiveness in improving biometric indicators of chronic disease through sustained lifestyle and behavior changes. A randomized controlled trial for the treatment of patients with diabetes in primary care using the evidence-based occupational therapy model known as Lifestyle Redesign $\circledast(L R)$ was found to impact significant health behavior change. ${ }^{7}$ Healthcare providers and staff involved in the LR study reported that OTs filled an important and unmet role on the primary care team. ${ }^{7}$ Despite the proven ability of OTs to treat chronic disease, uncertainty regarding reimbursement for occupational therapy services remains a significant barrier and often prevents primary care practices from adding OTs to their interprofessional teams. ${ }^{4,8}$

We sought to translate use of the LR model for diabetes management into real-world practice in conjunction with collectively gathering and disseminating patient-centered treatment recommendations from an external interprofessional team. The goal of this pilot study was to improve the health outcomes of patients with diabetes in primary care by implementing an OT-led interprofessional lifestyle modification program. We also sought to determine if such an intervention was feasible onsite at the primary care practice, or if occupational therapy services for chronic disease management would otherwise be reimbursable using a fee-for-service model. We hypothesized that the health outcomes of patients with diabetes in primary care would improve after participating in the OT-led interprofessional lifestyle modification program and that reimbursement would be obtained

\section{METHOD}

This study was approved by the Arizona State University Institutional Review Board and was registered as a Clinical Trial with the United States National Library of Medicine. All participants voluntarily provided written informed consent to participate.

\section{Treatment Environment}

Initially, one primary care practice agreed to hire an OT part-time to provide chronic disease management for patients with diabetes. Within days of initiating the onsite OT-led interprofessional lifestyle modification program, administrators of the practice expressed concern regarding the financial viability of offering occupational therapy services and determined that adding an OT on the primary care team was too risky. The practice was unsure whether occupational therapy would be reimbursed for chronic disease management. The study team then approached another primary care practice, which agreed to hire an OT. Unfortunately, this practice also withdrew from the hiring agreement days before the implementation was to take effect because of uncertainty regarding reimbursement. While both primary care practices agreed to still participate in the study by instead referring patients to an offsite occupational therapy clinic for services, only one of the practices actually referred patients. The offsite occupational therapy clinic was in a free-standing business plaza approximately 14 miles from the referring physician's office. The clinic used was a small neighborhood facility that primarily provides hand therapy and some general occupational therapy services across the lifespan. In this clinic, one to two therapists typically provide services at a time. Most patients are seen in an open area; however, the patients participating in the lifestyle modification program were seen in a private room.

\section{Intervention}

Referred patients were treated by an OT at the offsite occupational therapy clinic using a lifestyle modification program informed by the LR model.5,7,9 The OT-led intervention in this study used a holistic approach and aimed to work with patients across eight one-hour sessions modifying lifestyle behaviors and identifying barriers to adherence with medical instructions. The occupational therapy sessions incorporated activities across five themes (Table 1): diabetes knowledge and self-management skills, access and advocacy, activity and health, social support, and emotions and well-being. 5,7,9 Key differences in this study's intervention and past LR model occupational therapy interventions for diabetes management were the location of the visits and the assessments used (see Health Outcomes for further detail). 5,7,9 Sessions were predominantly conducted on an individual basis; however, 
depending on the patient's preference, some sessions involved family members. Upon initiating treatment, patients were educated about the role and scope of an OT. Patients were presented with the range of themes or aspects of their lives that affect their diabetes management that could be addressed during the occupational therapy sessions. The OT utilized a motivational interviewing approach to help the patient identify their priorities and establish goals. With the OT, patients collaboratively selected treatment activities from the various treatment themes based on their priorities, goals, and self-identified motivating factors. Each visit involved activities from two or more treatment themes. Patients were taught to incorporate diabetes self-management techniques recommended by their physicians into their unique habits, roles, and routines. As life circumstances changed, patients were encouraged to implement lifestyle modification strategies that they deemed realistic to successfully adapt their diabetes selfmanagement to their own unique context, skills, and resources. This intervention is easily replicated, as patients recognized their own unique barriers to adhering to the lifestyle modification recommendations and the medical instructions provided by their physicians and interprofessional care team. Patients identified alternative strategies that fit into their culture and lifestyle when they are unwilling or unable to follow advice. For example, one of the patients selected the theme of social support as a priority in his treatment and worked with his wife and daughter to establish a plan for family walks, as he felt individual exercise was unrealistic for him. The OT then worked with these family members to determine how they could realistically add this activity into their daily schedule. The OT also consulted with an external interprofessional team of providers from dietetics, epidemiology, medicine, occupational therapy, pharmacy, physical therapy, psychology, and social work. Patient-centered treatment recommendations from the interprofessional team were incorporated into the intervention.

Table 1. OT-led Intervention Themes. $5,7,9$

\begin{tabular}{|c|c|c|}
\hline Theme & Intervention Activities & Example Patient Resources \& Handouts \\
\hline $\begin{array}{l}\text { Diabetes } \\
\text { knowledge and } \\
\text { self-management } \\
\text { skills }\end{array}$ & $\begin{array}{l}\text { - Assess current understanding of diabetes and } \\
\text { related lab numbers } \\
\text { - Assess self-monitoring skills and habits } \\
\text { - Educate and provide options for modifications } \\
\text { as needed } \\
\text { - Reinforce past education of diabetes safety } \\
\text { protocols and complications }\end{array}$ & $\begin{array}{l}\text { - Educational handouts and links on basic } \\
\text { diabetes pathophysiology, self-monitoring, and } \\
\text { safety (e.g. hyper- and hypoglycemic episode } \\
\text { protocols) from credible sources such as the } \\
\text { American Diabetes Association (ADA), } \\
\text { American Association of Diabetes Educators } \\
\text { (AADE), and National Diabetes Education } \\
\text { Program (NDEP) }\end{array}$ \\
\hline $\begin{array}{l}\text { Access and } \\
\text { advocacy }\end{array}$ & $\begin{array}{l}\text { - Model and coach communication skills to } \\
\text { promote collaborative decision making with the } \\
\text { interdisciplinary healthcare team } \\
\text { - Assess access to necessary healthcare and } \\
\text { community services } \\
\text { - Scaffold and coach health system navigation } \\
\text { skills (e.g. identifying in-network providers, } \\
\text { understanding referral processes) } \\
\text { - Increase awareness of readily available } \\
\text { resources to address needs across the } \\
\text { spectrum of social determinants of health that } \\
\text { impact ability to perform diabetes self- } \\
\text { management tasks }\end{array}$ & $\begin{array}{l}\text { - Local healthcare and community agency } \\
\text { resources } \\
\text { - Educational handouts on interdisciplinary team } \\
\text { roles and templates to record names, titles, and } \\
\text { contact information for the patient's medical } \\
\text { team } \\
\text { - Worksheets to guide decision making (e.g. pros } \\
\text { and cons lists, templates or 'cheat sheets' for } \\
\text { patients to prepare questions for their providers } \\
\text { prior to office visits) }\end{array}$ \\
\hline $\begin{array}{l}\text { Activity and } \\
\text { health }\end{array}$ & $\begin{array}{l}\text { - Assess daily habits and routines } \\
\text { - Implement evidence-based habit-development } \\
\text { strategies }\end{array}$ & $\begin{array}{l}\text { - Educational handouts, links, and worksheets on } \\
\text { habit cycles and habit formation } \\
\text { - Calendars and activity diaries }\end{array}$ \\
\hline Social support & $\begin{array}{l}\text { - Assess existing social supports } \\
\text { - Role-play navigation of decision-making in } \\
\text { social situations } \\
\text { - Identify opportunities for soliciting additional } \\
\text { social support }\end{array}$ & $\begin{array}{l}\text { - Educational handouts on components of } \\
\text { support (emotional, informational, etc.) } \\
\text { - Worksheets to establish plans for identifying } \\
\text { needs for support, as well as, when and how to } \\
\text { solicit positive and constructive support }\end{array}$ \\
\hline $\begin{array}{l}\text { Emotions and } \\
\text { well-being }\end{array}$ & $\begin{array}{l}\text { - Assess stress and diabetes burnout } \\
\text { - Self-awareness training } \\
\text { - Educate and identify positive coping strategies } \\
\text { - Facilitate relaxation activities }\end{array}$ & $\begin{array}{l}\text { - Educational handouts and links on the impact of } \\
\text { stress on diabetes and stress management and } \\
\text { relaxation techniques } \\
\text { - Worksheets to identify and distinguish types of } \\
\text { stressors (temporary, chronic, personal, }\end{array}$ \\
\hline
\end{tabular}


interpersonal, and environmental) and potential strategies to address each type

\section{Health Outcomes}

The following assessments were used to track patient health outcomes pre- and post-intervention: 1) Patient-Reported Outcomes Measurement Information System (PROMIS-29), 2) Canadian Occupational Performance Measure (COPM), 3) Diabetes Empowerment Scale-Short Form (DES-SF), and 4) glycated hemoglobin (HbA1c) levels. These assessments were selected for their ease of use and relevance to the primary care setting. In the case of the $\mathrm{HbA1c}$, routine lab results from visits with the primary care physician were utilized.

\section{PROMIS-29}

PROMIS-29 is a valid measure that assesses the eight domains of physical function, anxiety, depression, fatigue, sleep disturbance, ability to participate in social roles and activities, pain interference, and pain intensity. ${ }^{10} \mathrm{~A}$ total of 150 points are possible for the PROMIS-29 score. Each domain, except for pain intensity, is scored using a five-point Likert scale and includes four items for a total of 20 possible points. The pain intensity domain only includes one item for a total of 10 possible points. The greater the pain intensity score (zero=no pain and 10=worst imaginable pain), the greater the patient's report of pain. A higher physical function score (one=unable to do and five=without any difficulty) signifies greater physical function. A higher anxiety or depression score (one=never and five=always) equates to more anxiety or depression. A lower fatigue or pain interference domain score (one=not at all and five=very much) indicates lower fatigue or pain interference. The sleep disturbance domain uses different scales for scoring its different items (one=very good and five=very poor; one=very much and five=not at all; one=not at all and five=very much). A higher sleep disturbance score represents greater sleep disturbance. Lastly, a higher social activity score (one=never and five=always) denotes greater ability to participate in social roles. ${ }^{11}$

\section{COPM}

The COPM is a reliable and valid tool that is used for the measurement of performance and satisfaction in all areas of life. ${ }^{12,13}$ During a semi-structured interview, the patient self-reports challenges with daily activities related to leisure, self-care, and productivity. The patient is then asked to rate these activates based on their importance (one=not very important at all and $10=e x t r e m e l y ~ i m p o r t a n t)$ and up to five activities are used for scoring. The patient is asked to rate performance (one=not able to do it at all and 10=able to do it extremely well) and satisfaction (one=not satisfied at all and 10=totally satisfied) for each of the identified activities. Calculated change scores for performance and satisfaction serve as meaningful reassessments. ${ }^{13}$ The greater the performance or satisfaction change scores, the greater the patient's improvement with the identified activities.

\section{DES-SF}

The original Diabetes Empowerment Scale (DES) contains 37 items and represents eight dimensions including need for change, developing a plan, overcoming barriers, asking for support, supporting oneself, coping with emotion, motivating oneself, and making appropriate care choices. ${ }^{14}$ The DES-SF contains eight items and was developed by selecting the item with the highest correlation from each of the original eight dimensions. ${ }^{15}$ Each item on the DES-SF is scored using a five-point Likert scale (one=strongly disagree and five=strongly agree) for a total of 40 possible points. A higher score represents an individual with greater self-efficacy in the management of their diabetes.

\section{HbA1c}

The $\mathrm{HbA} 1 \mathrm{c}$ biometric reflects the average blood glucose levels over a two-to-three-month period and is recommended as part of the standard of care for monitoring diabetes. Patients with $\mathrm{HbA} 1 \mathrm{c}$ levels $\geq 6.5 \%$ are diagnosed with diabetes. ${ }^{16}$

\section{Billing}

The OT maintained documentation of the patient sessions consistent with industry standard practice and used current procedural terminology (CPT) codes to reflect the treatment provided. Adhering to a fee-for-service model, the third party payers were billed for the services rendered.

\section{Data Analysis}

Descriptive statistics (mean $\pm S D$ ) were compiled for the patient health outcomes. Wilcoxon signed-rank tests were used to separately evaluate pre- to post-intervention differences across the different health outcomes for the group of three patients. With significance as p<0.05, all statistical analyses were performed using SPSS (v.26, IBM, Armonk, NY). 


\section{RESULTS}

\section{Participants}

Over a 16 week period, 31 patients were identified by the participating primary care physician and referred to take part in the OTled interprofessional lifestyle modification program. Four of the referred patients scheduled appointments (12.9\%) at the offsite occupational therapy clinic, however one ultimately declined occupational therapy services due to having a $\$ 50$ co-payment. The other three patients participated in the program reflecting a 9.7\% referral completion rate. As the offsite occupational therapy clinic accepted most insurance plans, each patient's type of insurance did not appear to be a factor determining participation.

The demographics and descriptive statistics of the sample are presented in Table 2. No females were represented (3M/OF), age ranged from 43 to 70 years ( $54 \pm 14.2$ years), and the predominant ethnic background was Hispanic. There was variation in the number of sessions attended and the duration of care provided. The number of sessions ranged from three to eight total visits ( $5.7 \pm 2.5$ visits) and the duration of care ranged from 2 to 15.7 weeks ( $8.6 \pm 6.9$ weeks). The copayment amount did not appear to impact the number of sessions attended by the participants in this study.

Table 2. Patient Demographics and Descriptive Statistics $(n=3)$.

\begin{tabular}{|l|l|l|l|l|l|l|l|}
\hline Patient & $\begin{array}{l}\text { Age } \\
\text { (years) }\end{array}$ & Sex & $\begin{array}{l}\text { Ethic } \\
\text { Background }\end{array}$ & $\begin{array}{l}\text { Number of } \\
\text { Sessions } \\
\text { Attended }\end{array}$ & $\begin{array}{l}\text { Duration of } \\
\text { Care } \\
\text { (weeks) }\end{array}$ & $\begin{array}{l}\text { Third Party } \\
\text { Payer }\end{array}$ & $\begin{array}{l}\text { Copayment } \\
\text { (\$/visit) }\end{array}$ \\
\hline one & 70 & male & Hispanic & 8 & 15.7 & Medicare & 0 \\
\hline two & 49 & male & Caucasian & 6 & 8.0 & private insurance & 35 \\
\hline three & 43 & male & Hispanic & 3 & 2.0 & Medicaid & 0 \\
\hline
\end{tabular}

\section{Outcomes}

\section{PROMIS-29}

The pre- to post-intervention change differences across all PROMIS-29 domains are reflected to the benefit or to the detriment of each patient (Fig. 1).

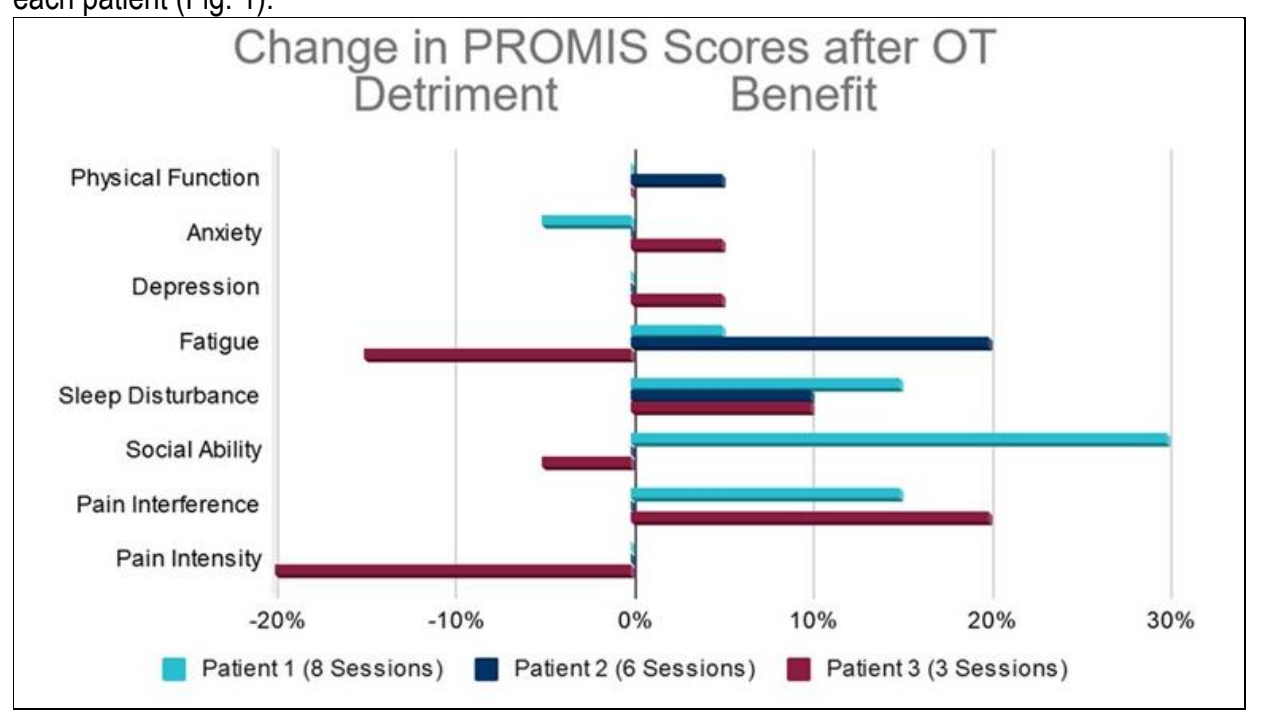

Figure 1. The pre- to post-intervention change differences across all Patient-Reported Outcomes Measurement Information System (PROMIS) domains.

There were no significant pre- to post-intervention differences for the group of three patients across the eight domains of physical function ( $p=0.32)$, anxiety $(p=1.00)$, depression $(p=0.32)$, fatigue $(p=0.59)$, sleep disturbance $(p=0.10)$, social ability $(p=0.66)$, pain interference $(p=0.18)$ and pain intensity ( $p=0.32)$, or in the total PROMIS-29 score ( $p=0.79$; Table 3$)$. 
Table 3. Pre- and Post-intervention Scores on the PROMIS-29 (mean \pm SD).

\begin{tabular}{|l|l|l|}
\hline Domain & Pre-intervention & Post-intervention \\
\hline physical function & $18.3 \pm 1.2$ & $18.7 \pm 1.5$ \\
\hline Anxiety & $5.7 \pm 1.5$ & $5.7 \pm 2.1$ \\
\hline Depression & $7.0 \pm 3.5$ & $6.7 \pm 2.9$ \\
\hline Fatigue & $13.3 \pm 4.6$ & $12.7 \pm 6.0$ \\
\hline sleep disturbance & $14.7 \pm 4.2$ & $12.3 \pm 4.7$ \\
\hline social ability & $12.3 \pm 3.5$ & $14.0 \pm 5.3$ \\
\hline pain interference & $11.7 \pm 8.0$ & $9.3 \pm 6.1$ \\
\hline pain intensity & $2.7 \pm 2.5$ & $3.3 \pm 2.9$ \\
\hline & pre-intervention & post-intervention \\
\hline total PROMIS score & $83.0 \pm 12.8$ & $81.3 \pm 8.5$ \\
\hline
\end{tabular}

Patient one demonstrated a decrease in fatigue (from eight to seven points), sleep disturbance (10 to seven points) and pain interference (11 to eight points), and an increase in the ability to participate in social roles (12 to 18 points). However, the other measures of physical function (19 points), depression (five points) and pain intensity (five points) stayed the same and anxiety increased (seven to eight points) for patient one. Patient two increased physical function (from 19 to 20 points), and decreased fatigue (16 to 12 points) and sleep disturbance (16 to 14 points). Anxiety (four points), depression (five points), social ability (16 points), pain interference (four points), and pain intensity (zero points) all stayed the same pre- to post-intervention for patient two. Patient three decreased anxiety (from six to five points), depression (11 to 10 points), sleep disturbance (18 to 16 points), and pain interference (20 to 16 points). Physical function (17 points) stayed the same for patient three, and fatigue (16 to 19 points) and pain intensity (three to five points) increased and the ability to participate in social activities decreased (nine to eight points).

\section{COPM}

Patient one had a change score of 2.7 in performance and 4.7 in satisfaction on the COPM. Patient two had a change score of 1.7 in performance and 0.3 in satisfaction. Patient three had a change score in performance and satisfaction of 4.0 and 4.8 , respectively, on the COPM.

\section{DES-SF}

While the DES-SF scores improved from 28 to 36 in patient one, 22 to 36 in patient two, and 38 to 40 in patient three, the pre$(29.3 \pm 8.1)$ to post-intervention (37.3 \pm 2.3$)$ changes on the DES-SF across the group of three patients did not reach statistical significance ( $p=0.11$; Fig. 2).

\section{COPM}

Patient one had a change score of 2.7 in performance and 4.7 in satisfaction on the COPM. Patient two had a change score of 1.7 in performance and 0.3 in satisfaction. Patient three had a change score in performance and satisfaction of 4.0 and 4.8 , respectively, on the COPM.

\section{DES-SF}

While the DES-SF scores improved from 28 to 36 in patient one, 22 to 36 in patient two, and 38 to 40 in patient three, the pre(29.3 \pm 8.1 ) to post-intervention (37.3 \pm 2.3 ) changes on the DES-SF across the group of three patients did not reach statistical significance ( $p=0.11$; Fig. 2 ). 
This LR model was originally designed to be conducted over a minimum of 10 sessions over the course of six months. ${ }^{5}$ In the hybrid effectiveness-implementation study by Pyatak et al (2019), patients completed an average $6 \pm 2.7$ visits in their primary care office. ${ }^{7}$ Only one of the three patients in the present study completed more than six visits. This patient expressed motivation to change their lifestyle at the beginning of the program, and was engaged throughout. Another patient had to leave town during the program and as a result, did not attend all of the visits. Otherwise, there were no specific trends identified that determined how many visits each patient would complete. With behavior-related treatments in outpatient settings, dropout rates tend to increase as the number of sessions increase, and such was the case with this study. ${ }^{7}$ Trends toward individual improvement were recorded for occupational performance and satisfaction and empowerment. This suggests further study regarding the minimum number of visits for optimal outcomes in a real-world setting is needed.

While unanticipated, the change in location from the onsite primary care practice to an offsite occupational therapy clinic provided an opportunity to evaluate the referral completion rate. The $9.7 \%$ referral completion rate for this study was consistent with data showing poor referral completion for behavioral health referrals when patients are referred offsite. ${ }^{17,18}$ Offering onsite occupational therapy services with the OT as part of a primary care team versus referring patients to an offsite location will improve participation rate, thus providing OTs the opportunity to further demonstrate the efficacy of delivering chronic disease management in primary care. ${ }^{7,19}$ Although the $\$ 50$ copayment was reported as a deterrent to participation for one patient, patient two participated in six visits with a $\$ 35$ copayment (Table 2). Payment of coinsurance or copayments is the standard practice in provision of health services in the United States and as of such, we do not anticipate that moderate copayments will serve as deterrents to providing occupational therapy services in primary care. However, in a practice with a different payment model that does not require a copayment, the barrier that precluded at least one patient from participating would be eliminated.

Documentation emphasized the medical necessity of services related to chronic disease management as an activity of daily living (ADL). Documenting the principle of level of assistance when reporting the ADL status of chronic disease management skills, such as activity modification, medication adherence, and diet modification is critical for reimbursement. Although services were approved and reimbursed by the three separate third party payers, the private insurance included in this study required company specific monthly progress reports and medical necessity review forms. When working with private payers for reimbursement of occupational therapy services, OTs and primary care practices alike should be aware of company-specific policies and requirements to maximize likelihood of reimbursement. Similarly, understanding state specific requirements to maximize the likelihood of reimbursement is important.

The primary limitation of this study was the small sample size, as this impedes generalization of these results. The secondary limitation was the change in intervention location. This location change caused limitation from the perspective of the therapist as well as the patient. Although the lifestyle modification program on which this study was based was designed to be used across a variety of settings, including patients' homes, community. and clinic settings, this study was originally designed to be completed across multiple primary care practices with the OT providing services as part of the interprofessional primary care team. ${ }^{5,7,9}$ However, administrators at the two participating practices expressed uncertainty regarding the financial viability of adding an OT, instead preferring to refer patients to an offsite occupational therapy clinic. As a result, the OT had limited access to the primary care team for real-time collaboration, which undermined the potential impact of the OT-led intervention. In addition, the short study period limited analysis to more immediate patient health outcomes; longitudinal follow-ups with patients would allow for analysis of any long-term intervention effects. Limitations imposed on the patients included the need to make additional appointments at a different time than their primary care visit and travel to another facility. In some cases with specific insurance types, this change in venue could require an additional copayment that may be avoided when services are provided at the primary care clinic at the same time as the physician visit. The patients with diabetes in this study were referred from community-based primary care practices that accept common insurance types. The withdrawal of these primary care practices illustrates the real-world pressures and barriers to the inclusion of OTs.

This study demonstrates that it is feasible to deliver an OT-led interprofessional lifestyle modification program, imparting behavioral strategies for improved adherence with medical recommendations to patients with chronic diseases, such as diabetes. Recommendations for future studies include evaluating health outcomes across a variety of intervention frequencies and durations to better define a target number of visits and overall treatment timeframe. To further assess feasibility and acceptability, trends in reimbursement across payer types should be evaluated as well as other identified barriers to OTs working in a primary care setting. This includes the perceptions of stakeholders such as primary care providers, primary care staff, and patients, to OTs addressing chronic disease management in primary care. Our findings suggest that the barrier of uncertainty regarding reimbursement is a misperception and is surmountable as occupational therapy treatment for a chronic disease management in a fee-for-service model is reimbursable. Given the complexity of funding for primary care, the financial feasibility of occupational 
therapy integration into primary care should be assessed across multiple payment models. Value-based models that focus on outcomes supported by behavior change will likely provide clearer support for the involvement of OTs on primary care teams. Despite the complexities of reimbursement yet to be explored, these findings demonstrate that it is reasonable to expect reimbursement for occupational therapy services in primary care and may serve to stimulate practice redesign efforts to include OTs as part of an integrated primary care model.

\section{DECLARATIONS OF CONFLICTING INTEREST}

These authors declare there are no conflicts of interest.

\section{REFERENCES}

1. Basu, R, Ory, MG, Towne, SD, Smith, ML, Hochhalter, AK, Ahn, SN. Cost-effectiveness of the chronic disease selfmanagement program: Implications for community-based organizations. Frontiers Public Health. 2015;3(27):1-8. [PMID: 25964945] https://doi.org/10.3389/fpubh.2015.00027

2. American Occupational Therapy Association. The role of occupational therapy in primary care. American Journal of Occupational Therapy. 2014;68(Suppl. 3):S25-S33. [PMID: 25456200] https://doi.org/10.5014/ajot.2014.686S06

3. Dahl-Popolizio, S, Doyle, S, Wade, S. The role of primary health care in achieving global healthcare goals: Highlighting the potential contribution of occupational therapy, World Federation of Occupational Therapists Bulletin. 2018;74(1):816. https://doi.org/10.1080/14473828.2018.1433770

4. Dahl-Popolizio, S, Rogers, O, Muir, SL, Carroll, JK, Manson, L. Interprofessional primary care: The value of occupational therapy. Open Journal of Occupational Therapy. 2017;5(3). https://doi.org/10.15453/2168-6408.1363

5. Pyatak, E, Carandang, K, Vigen, CLP, Blanchard, J, Diaz, J, Concha-Chavez, A, Sequeira, PA, Wood, JR, Whittemore, R, Spruijt-Metz, D, Peters, AL. Occupational therapy intervention improves glycemic control and quality of life among young adults with diabetes: The resilient, empowered, cctive living with diabetes (REAL Diabetes) randomized controlled trial. Diabetes Care. 2018;41(4):696-704. [PMID: 29351961] https://doi.org/10.2337/dc17-1634

6. Trembath, F, Dahl-Popolizio, S, VanWinkle, M, Milligan, L. Retrospective analysis: Most common diagnoses seen in a primary care clinic and corresponding occupational therapy interventions. Open Journal of Occupational Therapy. 2019;7(2):1-14. https://doi.org/10.15453/2168-6408.1539

7. Pyatak E, King M, Vigen CLP, Salazar E, Diaz J, Schepens Niemiec, SL, Blanchard, J, Jordan, K, Banerjee, J, Shukla, J. Addressing diabetes in primary care: Hybrid effectiveness-implementation study of Lifestyle Redesign $₫$ occupational therapy. American Journal of Occupational Therapy. 2019;73(5):1-12. [PMID: 31484021] https://doi.org/10.5014/ajot.2019.037317

8. Muir, S, Henderson-Kalb, J, Eichler, J, Serfas, K, Jennison, C. Occupational therapy in primary care: An emerging area of practice. OT Practice. 2014;19(15):CE1-CE7.

9. Pyatak, EA, Carandag, K, Davis, S. Developing a Manualized Occupational Therapy Diabetes Management Intervention: Resilient, Empowered, Active Living With Diabetes. OTJR. 2015;35:187-194. [PMID: 26594741] https://doi.org/10.1177/1539449215584310

10. Rose, AJ, Bayliss, E, Huang, W, Baseman, L, Butcher, E, Garcia, RE, Edelen, MO. Evaluating the PROMIS-29 v2.0 for use among older adults with multiple chronic conditions. Quality of Life Research. 2018;27:2935-2944. [PMID: 30088121] https://doi.org/10.1007/s11136-018-1958-5

11. PROMIS adult profile instruments. Patient-reported outcomes measurement information system. Dynamic tools to measure health outcomes from the patient perspective. 2020. http://www.healthmeasures.net/images/PROMIS/manuals/PROMIS_Adult_Profile_Scoring_Manual.pdf. Accessed on June 18, 2020.

12. Carswell, A, McColl, MA, Baptiste, S, Law, M, Polatajko, H, Pollock, N. The Canadian Occupational Performance Measure: A research and clinical literature review. Canadian J of Occ Ther. 2004;71(4):210-222. [PMID: 15586853] https://doi.org/10.1177/000841740407100406

13. Learn to use the COPM. The Canadian Occupational Performance Measure. http://www.thecopm.ca/learn/. 2020. Accessed on June 18, 2020.

14. Anderson, RM, Fitzgerald, JT, Funnell, MM, Marrero, DG. The diabetes empowerment scale. Diabetes Care. 2000;23(6):739-743. [PMID: 10840988] https://doi.org/10.2337/diacare.23.6.739

15. Diabetes Empowerment Scale (DES and DES-SF). Michigan Diabetes Research Center. http://diabetesresearch.med.umich.edu/Tools_Surveylnstruments.php. 2020. Accessed on June 18, 2020. 
16. Sherwani, SI, Khan, HA, Ekhzaimy, A, Masood, A, Sakharkar, MK. Significance of HbA1c test in diagnosis and prognosis of diabetic patients. Biomarker Insights. 2016;11:95-104. [PMID: 27398023] https://doi.org/10.4137/BMI.S38440

17. Auxier, A, Runyan, C, Mullin, D, Mendenhall, T, Young, J, Kessler, R. Behavioral health referrals and treatment initiation rates in integrated primary care: A collaborative care research network study. Translational Behavioral Medicine. 2012;2(3);337-344. [PMID: 24073133] https://doi.org/10.1007/s13142-012-0141-8

18. Kessler, $R$. Mental health care treatment initiation when mental health services are incorporated into primary care practice. Journal of the American Board of Family Medicine. 2012;25(2):255-259. PMID: 22403211. https://doi.org/10.3122/jabfm.2012.02.100125

19. Dahl-Popolizio, S, Manson, L, Muir, S, Rogers, O. Enhancing the value of integrated primary care: The role of occupational therapy. Fam Syst Health. 2016;34(3):270-280. [PMID: 27441739] https://doi.org/10.1037/fsh0000208 